\title{
ResearchArticle
}

\section{To study the pathogenicity of different isolated mycoflora in pigeonpea}

\author{
S. N. Sharma
}

\section{SUMMARY}

Pathogenicity test was carried out in the pots to detect the pathogenic nature of isolated fungal species. Pathogenicity Test was carried out by various methods-seed- inoculation method, soil inoculation method, leaf inoculation method. Test was carried out of pigeonpea variety UPAS-120. Pathogenicity and pathogenic behaviour of 15 fungal species isolated from pigeonpea seeds. Studying the pathogenic nature of the mycoflora by inoculation them wit seed, soil or leaf only 9 sp were found pathogenic. They were fusarium moniliformae, Alternaria alternate, Aspergillus flavus, A. niger, A. candidus cladosporium cladosporoides, Curvularia lunata and Rhizctonia solani. Eight of them were found seed borne and caused seed borne and caused seed and root-rot, seedling blight, necrosis of seedling ultimately resulted in seedling mortality. The fungi like Fusarium moniliformae, Alternaria alternata, Aspergillus flavus, Rhizctonia solani were also found soil borne and caused seed rot, root rot, seedling blight and seedling infection. Leaf inoculation with funagal species like Alternaria alternata, Cladosporium cladosporoides, curvularia lunata and Rhizoctinia solani showed leaf blight symptoms.

Key Words : Mycoflora, Inoculation, Pathogenicity, Mortality

How to cite this article : Sharma, S.N. (2019). To study the pathogenicity of different isolated mycoflora in pigeonpea. Internat. J. Plant Sci., 14 (2): 62-65, DOI: 10.15740/HAS/IJPS/14.2/62-65, Copyright@ 2019: Hind Agri-Horticultural Society.

Article chronicle : Received : 06.01.2019; Revised : 03.06.2019; Accepted : 12.06.2019 